\title{
Modeling and Control of Underactuated Three-Dimensional Overhead Crane Systems
}

\author{
Magdi S. Mahmoud*, Nezar M. Alyazidi and Abdalrahman M. Hassanine
}

Systems Engineering Department, KFUPM, P. O. Box 5067, Dhahran 31261, Saudi Arabia

\begin{abstract}
Overhead crane systems play a vital role in different factories to transport heavy loads. This paper provides an overview of recent developments in the modeling and control of three-dimensional overhead crane systems. It provides a categorized survey of the published work. Different control methodologies when applied to overhead crane are examined, outlined and assessed to aid for future work.
\end{abstract}

Keywords: Control, Modeling, Overhead Cranes, Underactuated systems.

\section{INTRODUCTION}

Cranes systems are used all over the world. Cranes are usually employed at factories, shipyards, construction sites, warehouses to transport heavy loads. One type of cranes is the overhead cranes, illustrated in Figure 1. They usually run in cartesian coordinates and have three main parts: the trolley, the bridge and the payload. The trolley moves along the bridge whereas the bridge moves perpendicular to the trolley motion. A gantry crane is the type of overhead cranes in which the crane travels on a mobile base. Overhead cranes in industry have complex and nonlinear dynamics, are in general subject to not only parameter fluctuations but also unmodelled dynamics, actuator nonlinearities, and disturbances. This work focuses on modeling and control of underactuated three dimensional (3D) overhead crane system. A review of the system modeling and control is presented.

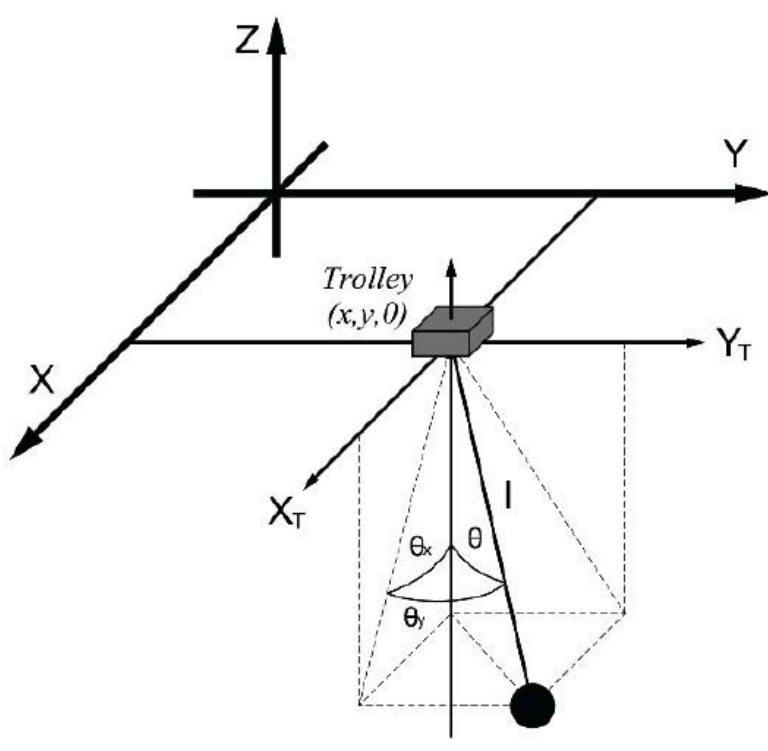

Figure 1: 3D Overhead Crane.

*Address correspondence to this author at the Systems Engineering Department, KFUPM, P. O. Box 5067, Dhahran 31261, Saudi Arabia;

Tel: + 966-13-860-7516; E-mail: msmahmoud@kfupm.edu.sa

\section{MODELING OF OVERHEAD CRANES}

Generally, there are two types of overhead crane models, the first type is two dimensional (2D) model [1-8], which is also called single-pendulum-type [9]. The 2D crane model is apparently nonlinear and has three states; trolley position, rope length and swing angle [7]. In general, during the operation, the rope length is fixed or slowly changing, hence, some studies $[1-6,8]$ assume the rope length is fixed, which reduces the number of states to two. In addition, if the swing angle is assumed to be small, a linearized model can be used to describe the system dynamics [1] On the other hand, the model accuracy and complexity can be increased by considering the friction between the moving parts [7], adding uncertainties to the system [8] or considering external disturbances [3].

The other type of overhead crane models is the 3D overhead crane or double-pendulum-type cranes [10]. In 1998, the general mathematical model of the 3D overhead crane is derived using Lagrangian equation [11]. The model is nonlinear and has five states; trolley position, bridge position, rope length and two swing angles. like $2 \mathrm{D}$ overhead cranes, assuming fixed rope length can simplify the model and reduce its states to four only [9, 12-20]. In other studies [11, 12, 18], the linearized model is obtained by assuming a fixed rope length and small swing angles for simplification. On the other hand, for a more accurate model, some investigations [10,11, 21-23] considered the damping coefficients while others $[10,15,18]$ considered the external disturbances like wind force to be added to the model. Unlike most of the studies, [13] takes the friction and air resistance into account in his model. Table 1 summarizes the findings of this section.

A typical dynamic model of the 3D crane system can be represented using the following equation [23]:

$M(q) \ddot{q}+D \dot{q}+C(q, \dot{q}) \dot{q}+G(q)=F$

where $q=\left[x, y, l, \theta_{x}, \theta_{y}\right]^{T}$ is the state vector, $F=$ $\left[f_{x}, f_{y}, f_{l}, 0,0\right]^{T}$ is the driving forces vector. The mass 
matrix $M(q)$, the damping matrix $D$, the Coriolis and centrifugal matrix $C(q, \dot{q})$ and the gravitational force vector $G(q)$ are defined as follows:

$$
\begin{gathered}
M(q)=\left[\begin{array}{ccccc}
m_{11} & 0 & m_{13} & m_{14} & m_{15} \\
0 & m_{22} & m_{23} & m_{24} & m_{25} \\
m_{31} & m_{32} & m_{33} & 0 & m_{35} \\
0 & 0 & m_{43} & m_{44} & m_{45} \\
m_{51} & m_{52} & 0 & 0 & m_{55}
\end{array}\right], D \\
=\left[\begin{array}{ccccc}
D_{x} & 0 & 0 & 0 & 0 \\
0 & D_{y} & 0 & 0 & 0 \\
0 & 0 & D_{l} & 0 & 0 \\
0 & 0 & 0 & 0 & 0 \\
0 & 0 & 0 & 0 & 0
\end{array}\right], \\
C(q, \dot{q})=\left[\begin{array}{llllll}
0 & 0 & c_{13} & c_{14} & c_{15} \\
0 & 0 & c_{23} & 0 & c_{25} \\
0 & 0 & 0 & c_{34} & c_{35} \\
0 & 0 & c_{43} & c_{44} & c_{45} \\
0 & 0 & c_{53} & c_{54} & c_{55}
\end{array}\right], G(q)=\left[\begin{array}{l}
0 \\
0 \\
g_{3} \\
g_{4} \\
g_{5}
\end{array}\right]
\end{gathered}
$$

Where $D_{x}, D_{y}$ and $D_{l}$ are the viscous damping coefficients. The nonzero elements of $M(q)$ are given by:

$$
\begin{aligned}
& m_{11}=M_{x}+m, \quad m_{13}=m_{31}=m \sin \theta_{x} \cos \theta_{y} \\
& m_{22}=M_{y}+m, \quad m_{23}=m_{32}=m \sin \theta_{x} \\
& m_{33}=M_{l}+m, \quad m_{14}=m_{41}=m l \cos \theta_{x} \cos \theta_{y} \\
& m_{44}=m l^{2} \cos ^{2} \theta_{y}, \quad m_{15}=m_{51}=-m l \sin \theta_{x} \sin \theta_{y} \\
& m_{55}=m l^{2}, \quad m_{25}=m_{52}=m l \cos \theta_{y}
\end{aligned}
$$

The nonzero elements of $C(q, \dot{q})$ are given by:

$$
\begin{gathered}
c_{13}=m \cos \theta_{x} \cos \theta_{y} \dot{\theta_{x}}-m \cos \theta_{x} \cos \theta_{y} \dot{\theta_{y}} \\
c_{14}=m \cos \theta_{x} \cos \theta_{y} \dot{l}-m l \sin \theta_{x} \cos \theta_{y} \dot{\theta_{x}} \\
-m l \cos \theta_{x} \sin \theta_{y} \dot{\theta_{y}}
\end{gathered}
$$$$
c_{15}=-m \sin \theta_{x} \sin \theta_{y} i-m l \cos \theta_{x} \sin \theta_{y} \dot{\theta_{x}}
$$$$
-m l \sin \theta_{x} \cos \theta_{y} \dot{\theta_{y}}
$$$$
c_{23}=m \cos \theta_{y} \dot{\theta_{y}}, \quad c_{25}=-m \cos \theta_{y} \dot{l}-m l \sin \theta_{y} \dot{\theta_{y}}
$$$$
c_{34}=-m l \cos ^{2} \theta_{y} \dot{\theta_{x}}, \quad c_{35}=-m l \dot{\theta_{y}}
$$$$
c_{43}=m l \cos ^{2} \theta_{y} \dot{\theta_{x}}, \quad c_{44}
$$$$
=m l \cos ^{2} \theta_{y} \dot{l}-m l^{2} \sin \theta_{y} \cos \theta_{y} \dot{\theta_{y}}
$$$$
c_{45}=-m l^{2} \sin \theta_{y} \cos \theta_{y} \dot{\theta}_{x}, \quad c_{53}=-m l \dot{\theta_{y}}
$$$$
c_{54}=m l^{2} \cos \theta_{y} \sin \theta_{y} \dot{\theta}_{x}, \quad c_{55}=m l \dot{l}
$$

The nonzero elements of $G(q)$ are given by:

$$
\begin{gathered}
g_{3}=-m g \cos \theta_{x} \cos \theta_{y}, \quad g_{4}=m g l \sin \theta_{x} \cos \theta_{y}, \quad g_{5} \\
=m g l \cos \theta_{x} \sin \theta_{y}
\end{gathered}
$$

Where $M_{x}$ is mass traveling along $X$-axis, $M_{y}$ is the mas traversing along $X$-axis, and $M_{l}$ is the mas moving along the hoisting cable, $m$ is the payload mass and $g$ is the gravitational acceleration.

\section{IIII. CONTROL OF OVERHEAD CRANES}

Controlling a crane system can be challenging due to its structure. The number of actuators in the crane system is less than the number of states to be controlled [24]. These types of systems are called under-actuated systems. The actuated and unactuated states in the crane model are usually separated using state transformation before designing the controller. The dynamic model in equation 1 can be separated and into two equations:

$M_{11}(q) \ddot{q_{a}}+M_{12}(q) \ddot{q_{u}}+C_{11}(q, \dot{q}) \dot{q_{a}}+C_{12}(q, \dot{q}) \dot{q_{u}}+$ $G_{1}(q)=\tau_{1}$

$M_{21}(q) \ddot{q_{a}}+M_{22}(q) \ddot{q_{u}}+C_{21}(q, \dot{q}) \dot{q}_{a}+C_{22}(q, \dot{q}) \dot{q_{u}}+$ $G_{2}(q)=0$

Where $M_{11}(q) \in \mathbf{R}^{3 \times 3}, \quad M_{12}(q) \in \mathbf{R}^{3 \times 2}, \quad M_{21}(q) \in$ $\mathbf{R}^{2 \times 3}$ and $M_{22}(q) \in \mathbf{R}^{2 \times 2}$ are sub-matrices of $M(q)$. $C_{11}(q, \dot{q}) \in \mathbf{R}^{3 \times 3}, C_{12}(q, \dot{q}) \in \mathbf{R}^{3 \times 2}, C_{21}(q, \dot{q}) \in \mathbf{R}^{2 \times 3}$ and $C_{22}(q, \dot{q}) \in \mathbf{R}^{2 \times 2}$ are sub-matrices of $C(q, \dot{q}) . G_{1}(q) \in$ $\mathbf{R}^{\mathbf{3} \times \mathbf{1}}$ and $G_{2}(q) \in \mathbf{R}^{\mathbf{2} \times \mathbf{1}}$ are sub-matrices of $G(q)$.

Equation (3) is rearranged as follows:

$\ddot{q_{u}}=-M_{22}^{-1}(q)\left[M_{21}(q) \ddot{q_{a}}+C_{21}(q, \dot{q}) \dot{q_{a}}+C_{22}(q, \ddot{q}) \dot{q_{u}}+\right.$ $\left.G_{2}(q)\right]$

By substituting (4) into (2), the actuated states of the system $q_{a}$ can be acquired by solving:

$\bar{M}_{1}(q) \ddot{q}+\bar{C}_{11}(q, \dot{q}) \dot{q_{a}}+\bar{C}_{12}(q, \dot{q}) \dot{q_{u}}+\bar{G}_{1}(q)=\tau$

Where

$$
\begin{aligned}
& \bar{M}_{1}(q)=M_{11}(q)-M_{12}(q) M_{22}^{-1}(q) M_{21}(q) \\
& \bar{C}_{11}(q, \dot{q})=C_{11}(q, \dot{q})-M_{12}(q) M_{22}^{-1}(q) c_{21}(q, \dot{q}) \\
& \bar{C}_{12}(q, \dot{q})=C_{12}(q, \dot{q})-M_{12}(q) M_{22}^{-1}(q) c_{22}(q, \dot{q}) \\
& \bar{G}_{1}(q)=G_{1}(q)-M_{12}(q) M_{22}^{-1}(q) G_{2}(q)
\end{aligned}
$$

Similarly, the unactuated states of the system $q_{u}$ can be acquired by solving:

$\bar{M}_{2}(q) \ddot{q}+\bar{C}_{21}(q, \dot{q}) \dot{q_{a}}+\bar{C}_{22}(q, \dot{q}) \dot{q_{u}}+\bar{G}_{2}(q)=\bar{H} \tau$

Where

$$
\begin{aligned}
& \bar{M}_{2}(q)=M_{22}(q)-M_{21}(q) M_{11}^{-1}(q) M_{12}(q) \\
& \bar{C}_{21}(q, \dot{q})=C_{21}(q, \dot{q})-M_{21}(q) M_{11}^{-1}(q) c_{11}(q, \dot{q}) \\
& \bar{C}_{22}(q, \dot{q})=C_{22}(q, \dot{q})-M_{21}(q) M_{11}^{-1}(q) c_{12}(q, \dot{q}) \\
& \bar{G}_{2}(q)=G_{2}(q)-M_{21}(q) M_{11}^{-1}(q) G_{1}(q) \\
& \bar{H}=M_{21}(q) M_{11}^{-1}(q)
\end{aligned}
$$

There are two general types of control methods utilized to control overhead cranes: open-loop control 
and closed-loop control. Open-loop control is divided into two general methods, optimal trajectory planning and command shaping. [25, 26] used optimal trajectory planning to control 2D crane system. [27] employed genetic-algorithms-based optimal trajectory planning while [28] used sliding-mode anti-swing trajectory control and [29] utilized linear programing for motion planning of a $2 \mathrm{D}$ crane system. Trajectory planning is offline and requires a prior knowledge of the desired trajectory and initial conditions of the system. The other open loop control technique is input shaping or command shaping. Command shaping is an online technique unlike trajectory planning. In [30, 31], linear input shaping is used to control a crane while [32] used nonlinear input shaping. This technique can also be combined with other techniques, e.g., particle-swarm-based input shaping is used to control nonlinear 3D overhead crane [33]. Input shaping has the advantage of dramatically reducing payload oscillations induced by crane motion. However, because input shapers are located at the feed-forward channel, a special design is needed to compensate for any error in the model. Table 2 illustrates some relevant references for open-loop crane control.

Table 2: Open-Loop Control of Overhead System

\begin{tabular}{|c|c|}
\hline Open-loop Method & References \\
\hline \hline Trajectory planning & {$[25,26,27,29]$} \\
\hline Command Shaping & {$[1,30,31,32,33]$} \\
\hline
\end{tabular}

The other type of control strategies is closed-loop control. Different closed-loop control methods are used to control overhead crane systems. Linear control uses linearized model to design the crane controller [11, 34]. Since the crane model has high nonlinearities, the linearized model is sometimes not accurate enough to provide information about position and swing angles of the load. Another disadvantage of linear control methods is that they have sensitivity to any change in the model e.g., the cable length, because they are design to control the system at a single cable length. Moreover, the presence of uncertain nonlinear factors like the wind, and moving parts frictions would also reduce the performance of linear crane control methods. Another control method is called partial feedback linearization $[19,22,35]$. The partial feedback linearization method simplifies the control problem, i.e., they are always employed in crane control as an initial simplification step [24].

Backstepping method is a method developed for designing controls for stabilizing a type of nonlinear dynamical systems with a special structure. These systems consist of subsystems in which the output from one subsystem can work as a stabilizing control for the subsequent subsystem. [36] used backstepping to control a crane with a flexible cable. The backstepping technique is widely integrated with other control methods, such as backstepping sliding mode control [37, 38], adaptive backstepping control [9]. Indeed, it employed Lyapunov function as the aim of designing to sustain the stability.

Another issue in crane control is the uncertainty of the model e.g., friction nonlinearity, external disturbances like wind, flexibility of the cables etc. [2, 9, $39,40]$ used adaptation laws to estimate unknown system parameters. Then, they utilized estimated values to control the crane. A combination of adaptive techniques with sliding mode and neural networks are utilized to control uncertain overhead crane [41]. An adaptive sliding-mode is used to control $2 \mathrm{D}$ crane with high-speed hoisting motion [42]. On the other hand, [8, 43] used robust linear quadratic regulator (LQR) on overhead crane system to overcome uncertainties in the model. [44] utilized a real-time robust technique for a crane control. [45] introduced a gain scheduling-based robust controller scheme for a crane with fluctuating parameters. In [46], a wave-based robust control is employed to control a crane with flexible cable. Robust control methods are suitable if the model has small uncertainties. On the other hand, for a wide range of parameter variation, adaptive control has a better performance, but it is sensitive to unstructured uncertainty [24]. Table 3 shows some relevant references for adaptive crane control.

Table 3: Adaptive Control of Overhead Crane System

\begin{tabular}{|c|c|c|}
\hline Crane Type & Cable Length & References \\
\hline \hline \multirow{2}{*}{ 2D Crane } & Fixed & {$[2,51]$} \\
\cline { 2 - 3 } & Varying & {$[42]$} \\
\hline \multirow{2}{*}{ 3D Crane } & Fixed & {$[9,39]$} \\
\cline { 2 - 3 } & Varying & {$[10,40,41,48]$} \\
\hline
\end{tabular}

Model predictive control (MPC) is one of the advanced control methods that has been employed in the process crane control. [3, 12, 47]. The disadvantage of MPC control is that it highly depends on the model of the system and that MPC has no guaranteed stability [24].

Sliding mode control is widely used in crane systems. There are two types of sliding mode controls used in the recent studies of crane control. One type is to design a special siding mode control for cranes. The other type is to use sliding mode with another control strategy in order to improve performance of the systems for example $[41,48]$ used neural networks- 
base adaptive hierarchical sliding mode control, partial feedback and sliding mode [35], adaptive fuzzy sliding-mode [49], sliding mode and Luenberger-type observer [23], sliding-mode-control-based robust finite-time [20] and backstepping aggregated sliding-mode [37].

Intelligent control is a class of control methods that use different intelligent computing algorithms, such as particle swarm optimization (PSO), neural networks, fuzzy logic, etc. [21] used fuzzy-logic based on the crane model and the control rules of experienced crane operators to control the crane. Fuzzy-logic can be used along with other control strategies like PID [50]. while others [49, 51] used adaptive fuzzy sliding-mode control. Other intelligent algorithms are also used in crane systems, like PSO with input shaping [33, 52], PSO-based robust [8], neural networks along with adaptive sliding mode control [48]. A combination of intelligent techniques is also used for crane control, e.g., neural-based fuzzy logic sliding mode control [8] and genetic algorithm-based two-stage fuzzy control [53]. Table 4 shows main techniques for 2D crane control while Table 5 shows main techniques for 3D crane control.

Table 4: Control of 2D Overhead Crane System

\begin{tabular}{|c|c|c|}
\hline Cable Length & Cable Length & References \\
\hline \hline \multirow{2}{*}{ Fixed } & Adaptive & {$[2,51]$} \\
\cline { 2 - 3 } & Sliding mode & {$[4,51]$} \\
\cline { 2 - 3 } & Intelligent control & {$[4,8,51,53]$} \\
\hline \multirow{2}{*}{ Varying } & Adaptive & {$[42]$} \\
\cline { 2 - 3 } & Sliding mode & {$[7,28,42]$} \\
\cline { 2 - 3 } & Intelligent control & {$[27]$} \\
\hline
\end{tabular}

Table 5: Control of 3D Overhead Crane System

\begin{tabular}{|c|c|c|}
\hline Cable Length & Cable Length & References \\
\hline \hline \multirow{2}{*}{ Fixed } & Adaptive & {$[9,20]$} \\
\cline { 2 - 3 } & Sliding mode & {$[9,20]$} \\
\cline { 2 - 3 } & Intelligent control & {$[14]$} \\
\hline \multirow{2}{*}{ Varying } & Adaptive & {$[10,40,41,48]$} \\
\cline { 2 - 3 } & Sliding mode & {$[23,35,37,38,41,48]$} \\
\cline { 2 - 3 } & Intelligent control & {$[21,38,41,48,52]$} \\
\hline
\end{tabular}

\section{CONCLUSIONS}

In this paper, we presented classified results pertaining to dynamic modeling and control design of three-dimensional overhead crane and double-pendulum-type systems. We focused on the developed methods for open-loop control as well as adaptive control.

\section{ACKNOWLEDGEMENT}

This research work is supported by the deanship of scientific research (DSR) at KFUPM through distinguished professorship award research project no. IN 161065.

\section{REFERENCES}

[1] Alhazza K, Masoud Z, Alotaibi N. A Smooth Wave-Form Shaped Command With Flexible Maneuvering Time: Analysis And Experiments. Asian Journal of Control 2016; 1376-1384

https://doi.org/10.1002/asjc.1204

[2] Hua YJ, Shine YK. Adaptive coupling control for overhead crane systems. Mechatronics 2017; 143-152.

[3] Ma X, Bao H. An Anti-Swing Closed-Loop Control Strategy for Overhead Cranes. Applied Sciences 2018. https://doi.org/10.3390/app8091463

[4] Yakut O. Application of intelligent sliding mode control with moving sliding surface for overhead cranes. Neural Computing and Applications 2014; 1369-1379. https://doi.org/10.1007/s00521-013-1351-9

[5] Liu H, Cheng W, Li Y. Dynamic Responses of an Overhead Crane's Beam Subjected to a Moving Trolley with a Pendulum Payload. Shock and Vibration 2019. https://doi.org/10.1155/2019/1291652

[6] Liu R, Li S, Ding S. Nested saturation control for overhead Crane Systems. Transactions of the Institute of Measurement and Control 2011; 862-875. https://doi.org/10.1177/0142331211423285

[7] Le TA, Lee S-G, Moon S-C. Partial feedback linearization and sliding mode techniques for 2D crane control. Transactions of the Institute of Measurement and Control $2014 ; 78-87$. https://doi.org/10.1177/0142331213492369

[8] Shao X, Zhang I, Zhang X. Takagi-Sugeno Fuzzy Modeling and PSO-Based Robust LQR Anti-Swing Control for Overhead Crane. Mathematical Problems in Engineering 2019 https://doi.org/10.1155/2019/4596782

[9] Xuan RL, Van TN, Viet AL, Thuy NVT, Xuan MP. Adaptive backstepping hierarchical sliding mode control for uncertain 3D overhead crane systems. International Conference on System Science and Engineering 2017.

[10] Abdullahi AM, Mohamed Z, Selamat H, Pota HR, Abidin MZ, Ismail F, Haruna A. Adaptive output-based command shaping for sway control of a 3D overhead crane with payload hoisting and wind disturbance. Mechanical Systems and Signal Processing 2018; 157-172. https://doi.org/10.1016/j.ymssp.2017.04.034

[11] Lee $\mathrm{H}-\mathrm{H}$. Modeling and Control of a Three-Dimensional Overhead Crane. Journal of Dynamic Systems 1998. https://doi.org/10.1115/1.2801488

[12] Wang X, Liu J, Zhang Y, Shi B, Jiang D, Peng H. A unified symplectic pseudospectral method for motion planning and tracking control of 3D underactuated overhead cranes. International Journal of Robust and Nonlinear Control 2019; 2236-2253.

https://doi.org/10.1002/rnc.4488

[13] Zhang M, Ma X, Rong X, Song R, Tian X, Li Y. An enhanced coupling nonlinear tracking controller for underactuated $3 d$ overhead crane systems. Asian Journal of Control 2018; 1839-1854.

https://doi.org/10.1002/asjc.1683

[14] Chang C-Y, Chiang K-H. Fuzzy projection control law and its application to the overhead crane. Mechatronics 2008; 607-615.

https://doi.org/10.1016/j.mechatronics.2008.05.003

[15] Zhang M, Zhang $Y$, Chen H, Cheng X. Model-independent PD-SMC method with payload swing suppression for 3D 
overhead crane systems. Mechanical Systems and Signal Processing 2019; 381-393. https://doi.org/10.1016/j.ymssp.2019.04.046

[16] Zhang M, Ma X, Rong X, Tian X, Li Y. Nonlinear coupling control method for underactuated three-dimensional overhead crane systems under initial input constraints. Transactions of the Institute of Measurement and Control 2018; 413-424.

https://doi.org/10.1177/0142331216658949

[17] Ismail RR, Ahmad M, Ramli M, Rashidi F. Nonlinear Dynamic Modelling and Analysis of a 3-D Overhead Gantry Crane System with System Parameters Variation. International Journal of Simulation.

[18] Giua A, Sanna M, Seatzu C. Observer-Controller Design for Three Dimensional Overhead Cranes Using Time-Scaling. Mathematical and Computer Modelling of Dynamical Systems 2001; 77-107. https://doi.org/10.1076/mcmd.7.1.77.3634

[19] Wu X, Xiongxiong $\mathrm{H}$. Partial feedback linearization control for 3-D underactuated overhead crane systems. ISA Transactions 2016; 361-370. https://doi.org/10.1016/j.isatra.2016.06.015

[20] Chwa D. Sliding-Mode-Control-Based Robust Finite-Time Antisway Tracking Control of 3-D Overhead Cranes. IEEE Transactions on Industrial Electronics 2017; 6775-6784. https://doi.org/10.1109/TIE.2017.2701760

[21] Cho S-K, Lee H-H. A fuzzy-logic antiswing controller for three-dimensional overhead cranes. ISA Transactions 2002; 235-243.

https://doi.org/10.1016/S0019-0578(07)60083-4

[22] Lee LAT-G, Kim V-HDM. Partial Feedback Linearization Control of a Three-Dimensional Overhead Crane. International Journal of Control, Automation, and Systems 2013; 718-727.

https://doi.org/10.1007/s12555-012-9305-z

[23] Almutairi NB, Zribi M. Sliding Mode Control of a Three-dimensional. Journal of Vibration and Control Overhead Crane 2009; 1679-1730. https://doi.org/10.1177/1077546309105095

[24] Qian D, Yi J. Hierarchical Sliding Mode Control for Under-actuated Cranes, Springer 2016.

https://doi.org/10.1007/978-3-662-48417-3

[25] Manson GA. Time-optimal control of an overhead crane model. Optimal Control Applications and Methods. Optimal Control Applications and Methods 1982; 115-120.

https://doi.org/10.1002/oca.4660030202

[26] Lee H-H. A New Motion-Planning Scheme for Overhead Cranes With High-Speed Hoisting. Journal of Dynamic Systems, Measurement, and Control 2004; 359-364. https://doi.org/10.1115/1.1767855

[27] Kimiaghalam B, Homaifar A, Bikdash M, Dozier G. Genetic algorithms solution for unconstrained optimal crane control, in Proceedings of the 1999 Congress on Evolutionary Computation-CEC99 1999.

[28] Lee $\mathrm{H}-\mathrm{H}$, Liang $\mathrm{Y}$, Segura D. A Sliding-Mode Antiswing Trajectory Control for Overhead Cranes With High-Speed Load Hoisting. Journal of Dynamic Systems, Measurement, and Control 2006; 842-845. https://doi.org/10.1115/1.2364010

[29] Khalid A, Huey J, Singhose W, Lawrence J, Frakes D. Human Operator Performance Testing Using an Input-Shaped Bridge Crane. Journal of Dynamic Systems, Measurement, and Control 2006; 128(4): 835-841. https://doi.org/10.1115/1.2361321

[30] Cruz JJD, Leonardi F. Minimum-time anti-swing motion planning of cranes using linear programming. Optimal Control Applications and Methods 2012; 34(2): 191-201. https://doi.org/10.1002/oca.2016

[31] Sorensen KL, Singhose W, Dickerson S. A controller enabling precise positioning and sway reduction in bridge and gantry cranes. Control Engineering Practice 2007; 15: 825-837.

https://doi.org/10.1016/j.conengprac.2006.03.005
[32] Daqaq MF, Masoud ZN. Nonlinear Input-Shaping Controller for Quay-Side Container Cranes. Nonlinear Dynamics 2006; 45: 149-170.

https://doi.org/10.1007/s11071-006-2425-3

[33] Maghsoudi MJ, Mohamed Z, Sudin S, Buyamin S, Jaafar H, Ahmad S. An improved input shaping design for an efficient sway control of a nonlinear 3D overhead crane with friction. Mechanical Systems and Signal Processing 2017; 364-378. https://doi.org/10.1016/j.ymssp.2017.01.036

[34] LHH. Modelling and control of 2-dimensional overhead crane. in Proceedings of the ASME dynamic systems and control division, Dallas, USA, 1997.

[35] Tuan LA, Lee S-G, Ko DH, Nho LC. Combined control with sliding mode and partial feedback linearization for 3D overhead cranes. International Journal of Robust and Nonlinear Control 2013. https://doi.org/10.1002/rnc.3061

[36] d'AndreHa-Novel B, Coron J. Exponential stabilization of an overhead crane with flexible cable via a back-stepping approach. Automatica 2000; 36(4): 587-593. https://doi.org/10.1016/S0005-1098(99)00182-X

[37] Tsai C-C, Wu HL, Chuang K-H. Backstepping Aggregated Sliding-Mode Motion Control for Automatic 3D Overhead Cranes. Advanced Intelligent Mechatronics 2012. https://doi.org/10.1109/AIM.2012.6265973

[38] Tsai C-C, Wu HL, Chuang $\mathrm{K}-\mathrm{H}$. Intelligent sliding-mode motion control using fuzzy wavelet networks for automatic 3D overhead cranes, in Proceedings of 51st annual conference of the society of instrument and control engineers of Japan, Akita, Japan 2012.

[39] Yang JH, Yang KS. Adaptive control for 3-D overhead crane systems. in 2006 American Control Conference, Minneapolis, Minnesota, USA, 2006.

https://doi.org/10.1109/ACC.2006.1656486

[40] Vo A-H, Truong Q-T, Ngo H-Q-T, Nguyen Q-C. Nonlinear tracking control of a $3-D$ overhead crane with friction and payload compensations. Journal of Mechatronics, Electrical Power, and Vehicular Technology 2016; 27-34. https://doi.org/10.14203/j.mev.2016.v7.27-34

[41] Anh LV, Hai LX, Thuan VD, Trieu PV, Tuan LA, Cuong HM. Designing an Adaptive Controller for 3D Overhead Cranes using Hierarchical Sliding Mode and Neural Network. in International Conference on System Science and Engineering (ICSSE) 2018. https://doi.org/10.1109/ICSSE.2018.8520162

[42] Park M-S, Chwa D, Eom M. Adaptive Sliding-Mode Antisway Control of Uncertain Overhead Cranes With High-Speed Hoisting Motion. IEEE Transactions on Fuzzy Systems $2014 ; 1262-1271$. https://doi.org/10.1109/TFUZZ.2013.2290139

[43] Grassin RT, et al. Robust control of a traveling crane. in Proceedings of the 1st European control conference, Grenoble, France 1991.

[44] Khatamianfar A, Savkin AV. Real-Time Robust and Optimized Control of a 3D Overhead Crane System. Sensors 2019. https://doi.org/10.3390/s19153429

[45] Ushida Y, Narita M, Ushiro T, Chen G, Takami I. Robust control for crane considering all varying parameters in the dynamics. in 11th IEEE International Conference on Control \& Automation (ICCA) 2014.

https://doi.org/10.1109/ICCA.2014.6871021

[46] Yang TW, O'Connor WJ. Wave Based Robust Control of a Crane System. in 2006 IEEE/RSJ International Conference on Intelligent Robots and Systems 2006.

https://doi.org/10.1109/IROS.2006.281997

[47] Deng J, Becerra VM. Application of constrained predictive control on a 3D crane system. in Proceedings of IEEE conference on robotics, Singapore 2004.

[48] Le V-A, Le H-X, Nguyen L, Phan M-X. An Efficient Adaptive Hierarchical Sliding Mode Control Strategy Using Neural Networks for 3D Overhead Cranes. International Journal of Automation and Computing 2019; 614-627. https://doi.org/10.1007/s11633-019-1174-y 
[49] Lee L-H, Huang C-H, Ku S-C, Yang Z-H, Chang C-Y. Efficient Visual Feedback Method to Control a Three-Dimensional Overhead Crane. IEEE Transactions on Industrial Electronics 2014; 4073-4083. https://doi.org/10.1109/TIE.2013.2286565

[50] Chang C-Y, Chiang T-C. Overhead cranes fuzzy control design with deadzone compensation. Neural Computing and Applications 2009; 749-757. https://doi.org/10.1007/s00521-009-0264-0

[51] Park M-S, Chwa D, Hong S-K. Antisway Tracking Control of Overhead Cranes With System Uncertainty and Actuator Nonlinearity Using an Adaptive Fuzzy Sliding-Mode Control. IEEE Transactions on Industrial Electronics 2008; 3972-3984.

https://doi.org/10.1109/TIE.2008.2004385
[52] Maghsoudi M, Ramli L, Sudin S, Mohamed Z, Husain A, Wahid $\mathrm{H}$. Improved unity magnitude input shaping scheme for sway control of an underactuated 3D overhead crane with hoisting. Mechanical Systems and Signal Processing 2019; 466-482.

https://doi.org/10.1016/j.ymssp.2018.12.056

[53] Diantong L, Jianqiaug $\mathrm{Y}, \mathrm{Mi}$ T. Proposal of GA-based two-stage fuzzy control of over-head crane. in roceedings of 2002 IEEE region 10 conference on computer, communications, control and power engineering, Beijing, China 2002.

DOI: https://doi.org/10.31875/2409-9694.2019.06.10

(c) 2019 Mahmoud et al.; Zeal Press

This is an open access article licensed under the terms of the Creative Commons Attribution Non-Commercial License (http://creativecommons.org/licenses/by-nc/3.0/) which permits unrestricted, non-commercial use, distribution and reproduction in any medium, provided the work is properly cited. 